\title{
O Jornal Vascular Brasileiro, CAPES e o Corpo Editorial
}

\author{
Winston Bonetti Yoshida*
}

O Jornal Vascular Brasileiro (J Vasc Bras) está perto de completar dez anos de atividade ininterrupta. Ao longo do tempo, foi se estabelecendo como principal fonte de informação científica vascular no Brasil, oriunda eminentemente de nossos associados. Teve crescimento contínuo desde 2002, com aporte sempre crescente de submissões, até que, em meados de 2009, com o anúncio da nova política da CAPES para qualificação de revistas, o nosso jornal teve rebaixamento significativo no novo critério Qualis, e as submissões de artigos oriundos de programas de pós-graduação começaram a minguar e migraram para revistas indexadas no Medline e/ou Institute of Scientific Information (ISI) da Thomson-Reuters. Deflagrado pela Sociedade Brasileira de Angiologia e de Cirurgia Vascular (SBACV) e pelo J Vasc Bras, iniciou-se, em 2009, um movimento de protesto dos editores de revistas nacionais junto à diretoria Científica da Associação Médica Brasileira (AMB) sobre a nova política da CAPES e o seu resultado pernicioso em termos do enorme prejuízo ao desenvolvimento das revistas nacionais. Os resultados das sucessivas reuniões foram objeto de editoriais em todas as revistas participantes das reuniões ${ }^{1}$. A síntese das propostas desse movimento foi brilhante e objetivamente ampliada e apresentada pelo Professor Maurício Rocha e Silva, em editorial, cujo conjunto de diretrizes vem de encontro aos anseios da comunidade de editores. O conteúdo deste editorial vale a pena ser acessado e consultado como verdadeira aula de bom senso ${ }^{2}$. Realmente, não parece fazer sentido a todos nós que, sendo todas as boas revistas nacionais indexadas no SciELO e Scopus (cujos fatores de impacto são superponíveis aos do ISI), a qualificação CAPES seja baseada somente no critério ISI, ao qual poucas revistas nacionais têm acesso, por serem revistas emergentes. Pelo critério CAPES, o J Vasc Bras, criado em 2002, tem que competir com revistas do porte do New England Journal of Medicine, criada há quase 200 anos.

Porém, independentemente do critério adotado, o J Vasc Bras precisa evoluir e obter as indexações internacionais, como ISI e Medline. Em primeira tentativa, não fomos aprovados, e esse resultado merece reforçar algumas reflexões. Os critérios desses dois indexadores são os mesmos: pontualidade, qualidade dos artigos, proporção de artigos originais e respectivas versões para inglês, qualidade do corpo editorial, cobertura nacional e importância de conteúdo para pesquisadores, estudantes e profissionais.

Com relação à pontualidade, tivemos alguns percalços com relação à troca de secretaria e programa computacional de gerenciamento editorial, mas que estão no caminho para resolução. Os fatores que realmente mais impactam na pontualidade são o número de submissões reduzido (cerca de 90 artigos por ano) e o atraso dos revisores e autores.

Temos seguidamente enfatizado que há expressiva produção científica na SBACV sob a forma de temas livres (cerca de 500 por congresso) $)^{3}$, mas poucos se convertem em artigos para revistas (apenas cerca de 6,3\% ) ${ }^{4}$. Em enquete do J Vasc Bras em andamento, pudemos constatar que os principais fatores para esse pequeno aporte seriam falta de tempo e de assessoria de redação científica e estatística. Porém, devemos também considerar que outras sociedades cirúrgicas similares à nossa enviam número expressivo de artigos para suas respectivas revistas (150 a 200 por ano), permitindo gerenciamento das edições do ano seguinte ao invés do trimestre corrente. Na nossa enquete, sugeriu-se também que Chefes de Serviço de Residência credenciados pela SBACV, para ter esta aprovação, deveriam relatar pelo menos um trabalho de conclusão de curso para ser publicado no J Vasc Bras pelos residentes. Sugeriu-se também que membros da Comissão Científica da SBACV e do Corpo Editorial do J Vasc Bras devessem publicar pelo menos um artigo por ano no nosso jornal, como requisito mínimo para pertencer a esses quadros. Finalmente, no sentido de ter cobertura nacional, é preciso que colegas de todas as regiões do Brasil, igualmente, contribuam com artigos para revista ${ }^{5}$.

A pontualidade depende muito do aporte de artigos, mas poderia ser melhorada substancialmente com processamento 
ágil dos mesmos. Neste particular, reconhecemos que ainda haveria espaço para ações mais rápidas da secretaria editorial e funcionamento adequado do sistema gestor de artigos (Sistema SciELO), o que é uma preocupação constante deste editor. Porém, o maior fator impactante na pontualidade é a revisão. Muitos revisores aceitam fazer a revisão, mas, por falta de tempo ou mesmo falta de compromisso com a revista, atrasam significativamente seus pareceres, mesmo após grande gasto de energia e tempo na cobrança sistemática e reiterada dos mesmos. Ainda com relação aos revisores, vale ressaltar que o Medline e ISI avaliam a qualidade do corpo editorial pelos artigos publicados pelos mesmos. Nesse sentido, lançamos e reafirmamos nossa campanha de convite aos colegas com doutorado e com publicações nacionais e internacionais para atuarem como revisores ad-hoc em período probatório, para podermos, ao longo do tempo, contar com grupo de revisores com a qualificação exigida por esses indexadores em nosso corpo editorial.

A qualidade das versões para o inglês tem sido avaliada pelo Dr. Ricardo da Rocha Moreira, colega do Paraná, que gentilmente tem se disposto a aferir textos dos artigos em português e suas respectivas versões para o inglês. Por ser trabalho de grande demanda, convidamos, por meio deste, outros colegas fluentes no idioma inglês que nos ajudem nessa laboriosa tarefa.
Não temos dúvida da importância do J Vasc Bras para a comunidade de especialistas e residentes em Cirurgia Vascular e Angiologia e para nossos alunos. A revista é um grande referencial científico, de novidades, diretrizes e revisões sobre assuntos pertinentes à nossa especialidade, sendo lida e consultada por $97,6 \%$ dos que responderam à nossa enquete, mas ainda tem grande potencial para ser muito melhor. As sugestões apresentadas neste editorial apontam parte do caminho. Contamos com o compromisso e entusiasmo de todos.

\section{REFERÊNCIAS}

1. Associação Médica Brasileira (AMB). Classificação dos periódicos no Sistema QUALIS da CAPES - a mudança dos critérios é URGENTE! J Vasc Bras. 2010;9(1):1-3.

2. Rocha e Silva, M. Qualis 2011-2013: os três erres. Rev Bras Cir Cardiovasc. 2010;25(4):VIII-IX.

3. Yoshida WB. Temas livres versus publicação. J Vasc Bras. 2005;4(4):319-20.

4. Yoshida WB, Holmo NF, Corregliano GT, Baldon KM, Souza e Silva N. Publicações indexadas geradas a partir de resumos de congressos de angiologia e cirurgia vascular no Brasil. J Vasc Bras. 2008;7(4):293-7.

5. Santos JGRP, Barbosa FT, Fraga TS. A qualidade dos ensaios clínicos randomizados publicados no Jornal Vascular Brasileiro. J Vasc Bras. 2011;10(1):9-16. 